\title{
Concurrent homozygous sickle-cell disease and severe haemophilia A: Thromboelastography profiles
}

Sickle-cell disease (SCD) is an inherited chronic haemolytic anaemia that is characterized by unpredictable episodes of pain and widespread organ damage. ${ }^{1}$ Our understanding of the pathophysiology of SCD has expanded tremendously beyond the polymerization of sickle haemoglobin. It is now apparent that the heterogeneity in this monogenic disease is driven by a multitude of factors, ranging from variations in neutrophils, endothelium and platelet activation, and the coagulation cascade. ${ }^{2}$ Thrombotic contribution to vaso-occlusion is involved in many of the complications and comorbidities associated with SCD. Although trials targeting platelets and coagulation in SCD have largely failed, the role of platelets and coagulation proteins in sickle-cell disease continues to be a vigorous area of study. The thromboelastograph (TEG) is an instrument that generates a profile of changes in elasticity during whole-blood coagulation. ${ }^{3}$ The use of TEG as a tool to study coagulation defects has utility in several clinical settings. ${ }^{3}$ Additionally, sickle-cell trait and disease patients demonstrate a hypercoagulable state in TEG profiles in several studies. ${ }^{4,5}$

The combination of SCD and haemophilia A has been reported twice in the medical literature. Glenn et al reported the case of a thirty-yearold man with SCD and mild haemophilia A who was treated with DDAVP for blunt abdominal trauma. ${ }^{6}$ Dhiman et al reported a case of sickle-beta thalassaemia with severe haemophilia A discovered incidentally after a dental procedure. ${ }^{7}$ Neither of these reports describe a longitudinal account of the patient. We describe a sibling pair with haemoglobin SS disease and severe haemophilia $A$, their clinical history and our use of the TEG to identify the state of whole-blood coagulation in this entity.

Sibling $A$ is a 26-year-old African American man with the following clinical profile: baseline haemoglobin electrophoresis of $\mathrm{HbS}$ 78.6\%, HbA2 2.9\% and HbF 18.5\%, factor VIII activity <1\%, 16 pain admissions, 7 bleeding admissions, no stroke and not on chronic transfusions. Sibling B is a 14-year-old African American boy with the following clinical profile: baseline haemoglobin electrophoresis of $\mathrm{HbS} 90.9 \%, \mathrm{HbA} 23.2 \%$ and $\mathrm{HbF} 5.9 \%$, factor VIII activity $<1 \%$, 3 pain admissions, 5 bleeding admissions, intracranial haemorrhage after trauma and on chronic transfusions since that incident (traumatic event occurred after the completion of the studies reported here). Neither sibling was on hydroxyurea, and both subjects were on prophylactic treatment with factor VIII replacement products.

Blood for TEG was drawn in the steady state for both patients, defined as no illness or pain in the preceding two weeks. We obtained TEG after a 72-hour washout period from FVIII on both patients as part of a baseline evaluation we do on all our patients with haemophilia. Citrated whole-blood $(340 \mu \mathrm{L})$ samples were activated using $20 \mu \mathrm{L}$ of human tissue factor dilution. The use of tissue factor is based on our centre's established normal ranges for the TEG with a tissue factor control. The sample was recalcified using $20 \mu \mathrm{L} \mathrm{CaCl}_{2}$. The TEG parameters were then compared to a set of 30 patients with severe haemophilia $A$ alone (including 2 half-siblings of Sibling $A$ and Sibling B) and a small cohort $(n=8)$ of HbSS patients in steady state in different studies at our institution. TEG parameters such as $\mathrm{R}$ time (clotting time), angle (rate of clot formation), maximum amplitude and maximum rate of thrombus generation (MRTG: the first derivative of the thromboelastographic curve can be plotted as a curve and reflects the rate of fibrin generation; from this curve, the maximum rate of thrombus generation is derived along with the time taken to reach the MRTG $\left(\mathrm{TMRTG}^{3}\right.$ ) were compared. The mean values obtained are listed in Table 1. Figure 1 depicts the MRTG curves of Siblings A and $B$ and representative patients with severe haemophilia $A$ alone (half-sibs 1 and 2) and HbSS disease alone. Thrombin generation was also assessed in the patients as part of a previous study (unpublished) in all of these patients, as described by Dargaud et al. ${ }^{8}$ Thrombin generation parameters analysed were lag time, peak height (peak), endogenous thrombin potential (ETP) and time to peak (Table 1). Since the TEG is affected by haemoglobin and platelet count, being a whole-blood assay, we have presented the mean blood counts including WBC, haemoglobin and platelet counts for each of the groups in Table 1.

The TEG in patients with concurrent severe haemophilia A and homozygous HbSS shows an enhanced clotting potential compared to patients with severe haemophilia A alone. We postulate that the differences noted on the TEG tracing and MRTG curves in Siblings $A$ and $B$ may potentially be explained by the differences in the $\mathrm{HbF}$ level. Sibling $\mathrm{A}$ has a higher $\mathrm{HbF}$ level, as seen with patients on hydroxyurea, and has a TEG profile that more closely resembles SHA, and conversely, Sibling B has a lower HbF level and has a TEG profile more closely resembling HbSS. When compared to patients with homozygous HbSS alone, they seem to have a lower thrombogenic potential, indicating that the two concurrent diagnoses may, in these patients, provide a beneficial balance between bleeding and thrombotic risks. The repeated cycles of erythrocyte sickling result in increased phosphatidylserine on surface of sickled erythrocytes. ${ }^{9}$ Published literature on the effect of foetal haemoglobin in thrombin generation suggests that elevated levels may impede exposure of phosphatidylserine (PS) on the RBC membrane. The effect seen in this 
TAB LE 1 Mean values of TEG parameters, thrombin generation profiles and blood counts

\begin{tabular}{|c|c|c|c|c|}
\hline & HbSS alone $(n=8)$ & $\begin{array}{l}\text { HbSS with severe haemophilia A } \\
(n=2)\end{array}$ & Severe haemophilia A $(n=30)$ & Controls $(n=19)$ \\
\hline \multicolumn{5}{|l|}{ TEG parameters } \\
\hline Angle (deg) & 76.6 & 50.5 & 39.4 & 62.9 \\
\hline $\mathrm{MA}(\mathrm{mm})$ & 73.1 & 68.2 & 59 & 62.1 \\
\hline \multicolumn{5}{|l|}{ Thrombin generation data } \\
\hline Lag time (min) & 2.35 & 2.45 & 4.91 & 4.20 \\
\hline ETP & 576 & 795 & 785 & 1052 \\
\hline Peak (mm) & 186.2 & 95.8 & 52 & 220 \\
\hline Time to peak & 4.2 & 6.9 & 14.5 & 7.0 \\
\hline Platelets & 353 & 311 & 247 & 297 \\
\hline
\end{tabular}

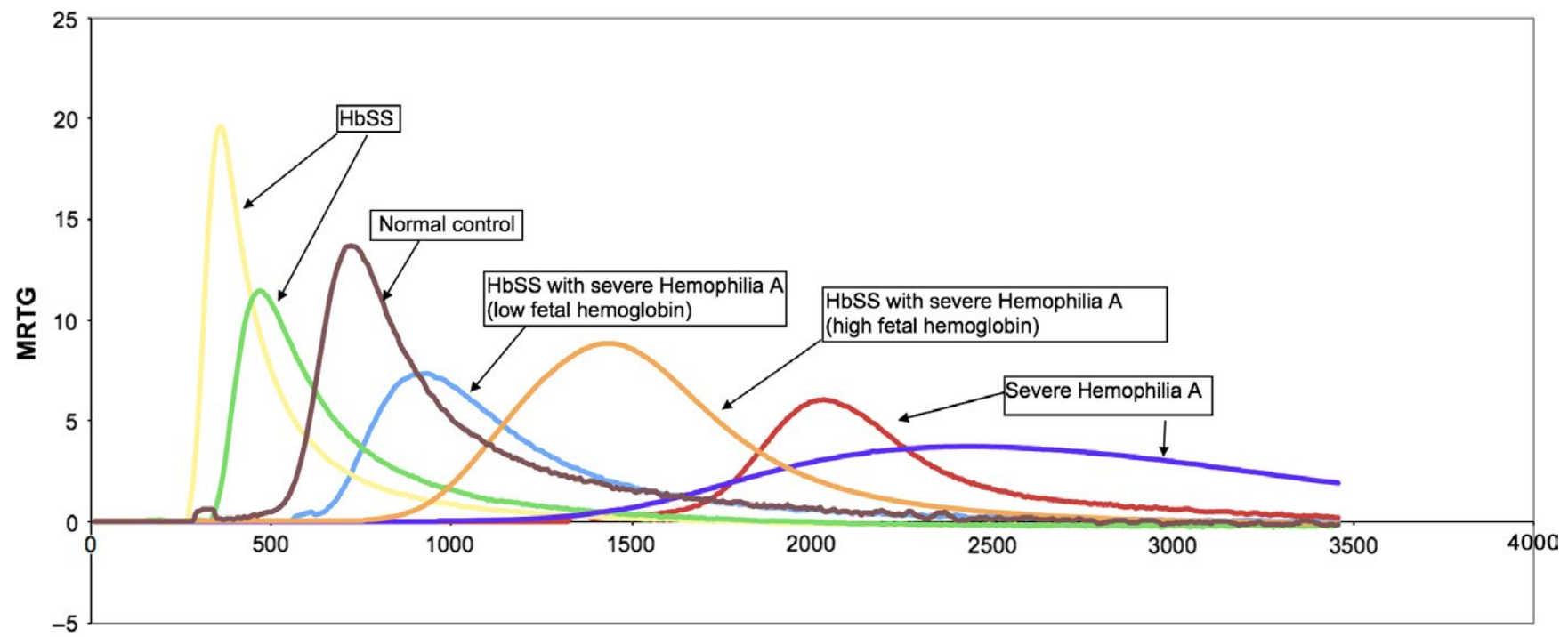

Time (s)

FIGURE 1 MRTG in varying clinical scenarios

sibling pair, Sibling A more than Sibling B, may be the result of the negation of PS exposure on the membrane, which results in loss of a "docking site" for haemostatic proteins on the phospholipid bilayer. Furthermore, the data on HbSS patients having increased factor VIII and von Willebrand factor activity are clear. Our sibling pair, though severe haemophilia A patients, have a mild phenotype. It is possible that the increased von Willebrand factor may be increasing the half-life of infused factor VIII and decreasing bleeding. In HbSS patients, the combination of decreased protein $\mathrm{C}$ and $\mathrm{S}^{10}$ with increased factor VIII, increased platelet activation and platelet-white blood cell aggregation contributes to vaso-occlusion. As shown in our sibling pair, this may be reflected in the TEG as short $\mathrm{R}$ time and, in its first derivative curve, increased rate of thrombin generation.

In summary, in patients with haemophilia A, the feedback loop causing a burst in thrombin generation is subdued given the low levels of factor VIII leading to a decreased production of thrombin as well as a fibrin clot that is vulnerable to fibrinolysis. In patients with sickle-cell disease, a combination of increased red cell adhesion, platelet activation and increased tissue factor may result in increased thrombin generation. Here, we show a measurable change in whole-blood coagulation in a sibling pair with the co-inheritance of these two severe diseases that have distinct effects on the coagulation system. 


\section{DISCLOSURES}

The authors stated that they had no interests which might be perceived as posing a conflict or bias.

\section{AUTHOR CONTRIBUTIONS}

Zaidi, Rao, Rajpurkar and Callaghan analysed the data and wrote the manuscript. Hollon performed laboratory work and analysed the data. Chitlur contributed tools, analysed the data and wrote the manuscript.

\section{ORCID}

Ahmar U. Zaidi (iD https://orcid.org/0000-0003-4551-661X Michael U. Callaghan (D) https://orcid.org/0000-0001-8742-0275 Madhvi Rajpurkar (iD https://orcid.org/0000-0002-5884-6776 Meera Chitlur (iD https://orcid.org/0000-0001-7656-0694

Ahmar U. Zaidi ${ }^{1}$ Latha Rao ${ }^{2}$ Michael U. Callaghan ${ }^{1}$ Madhvi Rajpurkar ${ }^{1}$ Wendy Hollon ${ }^{1}$ Meera Chitlur ${ }^{1}$ iD

${ }^{1}$ Carman and Ann Adams Department of Pediatrics, Children's Hospital of Michigan, Wayne State University School of Medicine, Detroit, Michigan

${ }^{2}$ Valley Children's Hospital, Madera, California

Correspondence

Ahmar U. Zaidi, Carman and Ann Adams Department of Pediatrics, Children's Hospital of Michigan, Wayne State University School of Medicine, Detroit, MI. Email:ahmar@wayne.edu

\section{REFERENCES}

1. Kato GJ, Piel FB, Reid CD, et al. Sickle cell disease. Nat Rev Dis Prim. 2018;4:18010.

2. Francis RB. Platelets, coagulation, and fibrinolysis in sickle cell disease: their possible role in vascular occlusion. Blood Coagul Fibrinolysis. 1991;2(2):341-353. http://www.ncbi.nlm.nih.gov/ pubmed/1893065. Accessed September 15, 2017.

3. Chitlur M, Warrier I, Rajpurkar M, et al. Thromboelastography in children with coagulation factor deficiencies. $\mathrm{Br} J$ Haematol. 2008;142(2):250-256.

4. Yee DL, Edwards RM, Mueller BU, Teruya J. Thromboelastographic and hemostatic characteristics in pediatric patients with sickle cell disease. Arch Pathol Lab Med. 2005;129(6):760-765.

5. Whelihan MF, Lim MY, Mooberry MJ, et al. Thrombin generation and cell-dependent hypercoagulability in sickle cell disease. J Thromb Haemost. 2016;14(10):1941-1952.

6. Glenn LD, Lovely RM, Goldsmith JC. Combined sickle cell anemia and mild haemophilia A: successful treatment of hemorrhage with DDAVP. Am J Hematol. 1991;37(1):64. http://www.ncbi.nlm.nih. gov/pubmed/2024646. Accessed May 1, 2018.

7. Dhiman P, Chaudhary R, Sudha K. Sickle cell- $\beta$ thalassemia with concomitant haemophilia A: a rare presentation. Blood Res. 2015;50(4):264.

8. Dargaud Y, Luddington R, Gray E, et al. Effect of standardization and normalization on imprecision of calibrated automated thrombography: an international multicentre study. $\mathrm{Br} J$ Haematol. 2007;139(2):303-309.

9. Kuypers FA, Lewis RA, Hua M, et al. Detection of altered membrane phospholipid asymmetry in subpopulations of human red blood cells using fluorescently labeled annexin V. Blood. 1996;87(3):11791187. http://www.ncbi.nlm.nih.gov/pubmed/8562945. Accessed May 16, 2018.

10. Lane PA. Plasma protein $\mathrm{C}$ levels in children with sickle cell disease. Am J Pediatr Hematol Oncol. 1991;13(3):365-366. http:// www.ncbi.nlm.nih.gov/pubmed/1793164. Accessed June 8, 2018.

\section{Factor IX inhibitors: Clinical and laboratory profiles of two patients with severe haemophilia $B$}

Development of alloantibodies (inhibitors) to exogenous factor IX (FIX) protein in patients with severe haemophilia B (SHB) occurs in approximately $3 \%-5 \%$ patients. Historically, immune tolerance induction (ITI) has been poorly effective for FIX inhibitors, with a success rate of just $15 \%-30 \% .{ }^{1}$ This stands in stark contrast to FVIII inhibitors where ITI success is generally reported at $75 \%-80 \%$.
Additionally, planned attempts at ITI for FIX inhibitors may be hampered by allergic reactions to FIX containing products and may require desensitization to $\mathrm{FIX}^{2}$

Although still not well understood, pathophysiology of FVIII inhibitors has received greater focus due to higher event frequency, with characterization of genetics and HLA-type risk factors as well 